\title{
O TRIBUTO E O CONTROLE SOCIAL NA ARGUMENTACÃO FUNCIONALISTA DE FRITZ KARL MANN
}

\section{Maurin Almeida Falcão ${ }^{1}$}

\section{Resumo}

O objetivo deste artigo é o de examinar e de discutir as funções sociopolíticas do tributo como meio de controle social na percepção de Fritz Karl Mann, um dos fundadores da sociologia fiscal. A partir de uma abordagem qualitativa, a análise se desenvolve em torno dos argumentos de Mann que justificam a relação entre a emergência do Estado fiscal e a recepção do tributo nos domínios da sociologia funcionalista. Em uma etapa seguinte, o trabalho descreve a noção de controle social a partir da ótica funcionalista e do fato social, o que se constitui no elo entre as partes que compõem a presente discussão. Em sua última parte, o artigo discute as ideias de Mann e o seu esforço com vistas à estruturação dos mecanismos de controle social, objetivo precípuo do artigo. Ao final, verifica-se que Mann abriu com as suas pesquisas, um novo horizonte para o tributo que não o de simples provedor dos cofres públicos. De fato, o ônus tributário decorrente da vida em sociedade perpassa diversas esferas das ciências sociais e a análise transdisciplinar se impõe, portanto, como condição para a sua validade nas sociedades democráticas.

Palavras-chave: Tributo, Função sociopolítica, Teoria funcionalista, Controle social.

\section{INTRODUCÃO}

A instrumentalização do tributo, para além do seu papel ordinário de financiador da despesa pública, se constituiu em notável progresso no campo das finanças púbicas. De fato, a sua relação estreita com o fato social atribuiu-lhe uma missão mais nobre que a de simples provedor dos cofres do Estado ao introduzi-lo no universo sociopolítico. Tal evolução fez com que o ônus fiscal da vida em sociedade transpusesse os domínios da sua abordagem jurídica tradicional, lançando-o ao crivo de outras ciências sociais tais como a economia, a psicologia, a sociologia e as ciências políticas. Presente em todas as etapas da evolução da vida em sociedade, desde os impérios até a configuração do Estado democrático de direito, o sistema tributário passou a refletir o progresso político das instituições. Em consequência, a emergência de uma teoria normativa, de aplicação larga no campo das finanças públicas por explicar os limites de ação do Estado, despertou o interesse dos diversos ramos do conhecimento humano. A tradição da escola germânica enriqueceu o debate a partir da notável contribuição dos austríacos

\footnotetext{
${ }^{1}$ Professor Doutor do Mestrado em Direito da Universidade Católica de Brasília. Membro-fundador do Institut Internationale de Sciences Fiscales-2ISF. Pós-doutorado realizado no Grupamento Europeu de Pesquisas em Finanças Públicas-GEFIP da Universidade Paris I-Panthéon-Sorbonne. E-mail: mfalcao@pos.ucb.br
} 
fundadores da sociologia fiscal, Rudolf Goldscheid (1870-1931), Fritz Karl Mann (1883-1978) e Joseph Schumpeter (1870-1950). Os horizontes delineados por estes pensadores ampliaram as funções do tributo e ressaltaram a sua importância na construção da sociedade moderna. $\mathrm{O}$ advento do Estado fiscal se constituiu no cerne do debate ao final da primeira metade do Século XX e, por isso, deu origem a vigorosas teorias com o intuito de explicar o real papel do tributo nos diferentes estágios políticos pelos quais passaram o Estado e as suas instituições nas suas formas arcais e modernas. Uma importante conexão foi realizada entre as diversas formas de segmentação social, a distribuição do poder e da riqueza social, fatos esses que passaram a ter o tributo como centro de disputa política e de reajustamento de poder. A implicação de todos no processo da grande sociedade solidária desencadeado na sociedade pós-Revolução Industrial impôs a necessidade de controle social, perspectiva devidamente considerada por Mann no seu esforço de integrar o tributo no contexto sociopolítico.

Embora o tema não tenha sido devidamente incorporado pela literatura específica, o resgate realizado por Leroy (2010), dos trabalhos realizados pelos fundadores da sociologia fiscal, permitiu que um olhar fosse lançado sobre o conjunto de suas obras, consolidando a percepção sociológica do tributo uma vez que este não poderia ser desassociado, jamais, do seu forte conteúdo sociopolítico. Colocado às vezes como meio de coesão ou como forma de disputa pela riqueza social, o tributo, desde cedo, se constituiu em peça estrutural da organização social, tendo perpassado pelas diversas formas de organização coletiva até o modelo político ora em uso. Fritz Karl Mann se insere, pois, na tríade dos fundadores da sociologia fiscal devido a sua valiosa contribuição ao entendimento do tributo como meio de instrumentalização da teoria funcionalista.

Assim, a partir de uma abordagem sociopolítica o presente trabalho se propõe a examinar a argumentação de Mann em torno do tributo como forma de controle social. Nesse sentido, a primeira parte se voltará para a descrição dos pressupostos que este entende como necessários à construção do cenário que se pretende analisar. Em um segundo momento, serão expostos os fundamentos do controle social com vistas a justificar a sua articulação com o tributo. Nesse aspecto, serão privilegiados os elementos basilares da teoria funcionalista, o que permitirá uma melhor compreensão dos pressupostos que permitiram estabelecer o liame principal desse trabalho: o tributo como forma de controle social. Finalmente, a última parte será consagrada à análise das funções sociopolíticas do tributo, ou seja, as formas de controle social propostas do Mann e que se inserem de forma adequada no contexto das sociedades modernas, caracterizadas por uma solidariedade coercitiva.

\section{O TRIBUTO E O CONTROLE SOCIAL NA ARGUMENTAÇÃO DE MANN}

Antes de discorrer sobre o trabalho de Mann e a sua visão funcionalista do tributo, é importante observar que o cientista social não se encontrava isolado em sua empreitada. Na primeira metade do Século XX, diferentes 
sociólogos passaram a dedicar uma atenção especial a um tema que passava, cada vez mais, a ser recorrente: o da sociologia fiscal. Leroy (2010a, p. 01), ao ressaltar a importância da matéria expôs que "Issue de la sociologie financière apparue avec la Première Guerre Mondiale, la sociologie fiscale constitue une approche majeure pour comprendre l'évolution des sociétés occidentales". Hobson (1997, p. 05) ressaltou esse interesse crescente advertindo, de passagem, sobre a origem alemã dessa inestimável contribuição ao melhor entendimento da vida em sociedade:

Know as Finanzwissenschaft in Germany (where it originated) under the auspices of Fritz Karl Mann (1943), Rudolf Goldscheid (1958), Joseph Schumpeter (1918/1954) and Norbert Elias (1939/1944) to name a but few, fiscal sociology has more recently attracted considerable attention among historical sociologists. Indeed, the sociology of taxation has become a growth area for neo-Weberian sociologists, being employed to explain some of the most importante structural developments in the last five hundrede years.

Tendo permanecido acantonado, por longo tempo, em sua função clássica de provedor dos cofres do Estado o tributo passaria, a partir do esforço intelectual de Mann, a ser percebido também por suas funções sociopolíticas. Os cânones da ciência social das finanças (públicas) que "Fritz Karl Mann enriquecerá pela introdução das funções sociopolíticas do tributo" (LEROY, 2010a, p. 40), seriam responsáveis por uma nova compreensão dos compromissos firmados com vistas à eficiência coletiva e sintetizados no contrato social.

Por conseguinte, Mann (1943, p. 225) inaugurou um novo capítulo na compreensão do fenômeno tributário ao asseverar que "People are less aware, in recent times, its character underwent another important change: broadly speaking, taxation has gradually moved from the sphere of public finance into to sphere of sociology". Na esteira da nova ciência social, tal esforço permitiu o acoplamento do tema sobre tributação e sociedade aos vastos domínios da sociologia, a qual despontou como disciplina científica a partir da mudança social ocorrida na sociedade pós-Revolução Industrial. Tendo se incorporado às lições funcionalistas de Durkheim para explicar o papel do tributo não apenas como uma simples ferramenta das finanças públicas, Mann (1943, p. 225) reforçou os alicerces da sociologia fiscal ao justificar que "More and more with conscious intente, its fiscal function has been combined with a function of social control". Os laços entre solidariedade e tributo resultam em uma aliança que leva à representação deste como um dever materializado na obrigação tributária, conforme ressaltou Rosa (2015). De fato, a implicação de todos na grande sociedade solidária, segundo os padrões de coercibilidade do fato social de Durkheim, encontrou no tributo uma espécie de caixa de ressonância. Nesse entendimento, fica reiterado que da própria definição de Durkheim acerca do fato social, onde o mesmo enfatiza a coerção exterior que este exerce sobre os indivíduos, a divisão do trabalho social impôs, por meio do direito restitutivo, o restabelecimento da ordem natural das coisas. Dessa lição, arremata-se que a natureza coercitiva do fato social leva, inexoravelmente, à função social do tributo pois este, por meio da progressividade, se inscreve como o amálgama da vida em sociedade. Com efeito, o processo de organização vertical da sociedade pós-Revolução Industrial, demandou um vigoroso processo de redistribuição da riqueza produzida, tornando-se 
um valioso instrumento de coesão social. A demanda por democracia, equidade e justiça social, com supedâneo em um direito social em formação, colocou todos sob o manto do solidarismo social. O conjunto de fatos sociais que levaram à mudança social impôs, nesse contexto, a coerção a qual se materializou na participação de todos no financiamento do recém-inaugurado Estado-providência. Dessa forma, a repartição do custo do ônus da vida em sociedade se daria por meio do consentimento ao tributo, este visto como o único meio de atender os imperativos da democracia, da equidade e da justiça social. Breve, a positivação dos direitos sociais consolidou os laços entre solidariedade e tributo, conforme asseverou Rosa (2015). Ao destacar a importância do contratualismo nas sociedades modernas, Donzelot (1994 p. 80) observou o papel de Durkheim em face da solidariedade ao ressaltar, de forma percuciente, que esta se constituiria na base do processo em curso, justificando dessa forma, o liame tácito entre os membros do corpo social:

D'une formule sociale à l'autre, la solidarité change de nature; mais elle demeure la loi constitutive de la société. Sans doute les sociétés modernes accordent-elles de plus em plus de place à la forme contractuelle.

Nessa inteligência, Mann (1943, p. 225) conferiu ao tributo um papel indissociável da vida em sociedade ao acrescentar as suas argumentações que "Current taxation is the inseparable twin of the modern State". Sem dúvida, a própria ação do Estado e de suas instituições, se constituiria no âmago do processo intervencionista declarado na sociedade pós-Revolução Industrial. Deve ser ressaltado que esse conjunto de fatos repercutiram no surgimento de uma teoria normativa voltada para a definição dos limites desta intervenção. Em realidade, ao atuar nas três funções clássicas inerentes às finanças públicas modernas - a alocação, a redistribuição e a estabilização o Estado e as suas instituições tiveram como supedâneo, o tributo em suas novas configurações democráticas.

Ao estender a sua análise, Mann (1943, p. 225) afirma que o tributo seria o gêmeo inseparável do Estado moderno, o que se trata de uma visão compartilhada por diversos autores contemporâneos. Por exemplo, Bouvier (2012, p. 01) asseverou que «o tributo ocupa um lugar central no funcionamento das sociedades contemporâneas e que se constituiria em um dispositivo-chave do sistema político, econômico e social ». Por sua vez, Nikonoff e Drezet (2005, p. 31) observaram que "O tributo é um produto da história e das relações sociais", colocando-o assim como um marco da civilização. Depreende-se de tal modo que, por perpassar diversas segmentos da vida em sociedade, o tributo não poderia permanecer restrito a um campo apenas de conhecimento, devendo os seus efeitos serem analisados nas diferentes perspectivas da ação do Estado.

Desses pressupostos depreende-se que as transformações pelas quais passaram o Estado, mesmo nas suas formas arcaicas, tiveram no ônus fiscal uma forma de sustentação sociopolítica, inclusive no que se refere à manutenção do poder. Desde a tributação parasitária, passando pelo sistema feudal e pelo patrimonialismo, até às sociedades industriais, a lenta formatação de um Estado fiscal se constituiu em um dos traços mais importantes da evolução sociopolítica que marcou o transcorrer dos séculos, tendo o seu ápice na formação da agenda social do Século XIX. De forma categórica, pode-se afirmar que esse processo se constituiu na força das transformações que vol.09, no. 04, Rio de Janeiro, 2016. pp. 1841-1864 
levaram a uma nova paisagem social. Nessa direção, Aron (1964, p. 199) questionou sobre as tendências principais da evolução social da sociedade industrial respaldada, sobretudo, em um forte processo de urbanização. Em realidade, esse processo significou, de acordo com Falcão (2013, p. 96), "O rompimento com a sociedade clássica trouxe novas formas de democracia e de justiça social, possibilitando dessa forma, a mobilidade social. Por isso, impôs diferentes formas de pensar em diferentes áreas do conhecimento humano.” Portanto, o encadeamento dos fatos responsáveis pela mudança social operada na fase pós-Revolução Industrial, onde o anseio por mais democracia, mobilidade social e justiça teve o seu ápice com a emergência do intervencionismo estatal e da socialdemocracia, lançou as bases da grande sociedade solidária. Por isso, um amplo controle social se faria necessário a partir daí e teria respaldo no consenso nascido no seio da teoria funcionalista. Mann (1943, p. 226) imprimiu um verniz sociopolítico ao tributo ao incorporar-lhe as funções que ele consideraria como sendo as três formas de controle social:

The following discussion is focused on three forms of social control exercised by taxation: (1) correction of socially undesirable human behavior; (2) readjustement of economic power between social groups and classes; and (3) combatting the social abuses of capitalism and facilitating the transition to another economic order.

A partir de sua afirmativa de que o tributo permitiria a preservação da estrutura social, Mann lançou um olhar sobre a funções do tributo além daquelas estipuladas por Musgrave (1959). Em consagrada obra sobre finanças públicas, Musgrave definiu as funções estatais que se constituiriam na pedra angular das finanças públicas. De fato, há uma convergência entre Mann e Musgrave quando estes admitem que o tributo teria o condão de induzir comportamentos mais interessantes em nome da eficiência coletiva. Breve, deve ser ressaltado que Musgrave, de um lado, definiu a questão sob um prisma econômico enquanto que Mann optou por uma abordagem voltada para a função social do tributo.

Não é por demais insistir que Mann, ao se referir à necessidade de preservação da estrutura social, vislumbrou nas lições funcionalistas, a importância da coesão social, o que impregnou toda a sua argumentação em torno da sociologia fiscal. Impôs-se, dessa forma, a constatação inexorável do tributo como um produto das relações sociais. Nesse contexto, a sociologia fiscal se revelou um domínio capaz de aglutinar as diferentes percepções do ônus fiscal decorrente da vida em sociedade. Campbel (1993, p. 116), observou com perspicácia e uma visão que ultrapassa largamente o enfoque dogmático do tributo, a efetiva dimensão da sociologia fiscal:

Fiscal sociology differs from other approaches to the study of taxes and public finances because it considers how these things affect and are affected by a wide range of political, economic, cultural, institutional, and historical factors.

Sem dúvida, tal redimensionamento se constituiu em valor caro para Mann que se enveredaria por esse caminho ao afastar a ideia de que o tributo teria apenas uma simples função financeira, dogma prevalecente até então. Retomando as influências funcionalistas de Mann, há que se mencionar a criação da grande sociedade solidária por ocasião da mudança social ocorrida na sociedade pós-Revolução Industrial. Tal evento seria o fiador 
da intervenção estatal, tendo gerado uma excepcional controvérsia em razão da intensa circulação de ideias e da emergência de novas teorias. De forma categórica, Aron (1962, p. 02) ao se referir às ideologias políticas e socialistas produzidas na primeira metade do Século XIX, sustentou que "Nous vivons encore aujourd'hui sur le stock d'idées développées par les penseurs de cette époque.... Aliás, dentre elas, pode ser ressaltada a teoria normativa sobre o papel do Estado e de suas instituições como forma de justificar a intervenção pública, conforme preceituou Bozio e Grenet (2010, p. 08).

Deve-se insistir sobre o fato de que nesse terreno fértil, Mann pôde semear a sua contribuição ao demonstrar interesse às funções sociopolíticas do tributo (LEROY, 2010a, p. 50). Nesse aspecto, é importante notar que a construção do social implicou todos, de forma coercitiva, impondo sanções àqueles que se furtassem a participar da ação coletiva. Por isso, Mann decidiu por estender às funções clássicas do tributo, as bases de um controle social com o escopo precípuo de corrigir comportamentos não desejáveis, a reorganização do poder econômico entre grupos sociais, a luta contra os abusos do capitalismo e, finalmente, a transição para uma outra ordem econômica. De fato, depreende-se do esforço do cientista alemão que o controle social pretendido abarcaria não apenas as antigas lições da sociedade solidária mas também as variáveis decorrentes da expansão da economia capitalista e do keynesianismo nos anos trinta do Século XX. O encadeamento da solidariedade dentro de um sistema como a divisão do trabalho social, por exemplo, levou à ideia de um sistema social interagindo de forma autônoma com outros sistemas sociais, o que seria, segundo Parsons (1973, p. 08), a definição de sociedade.

Em seu esforço argumentativo, Mann esboça ainda conceitos que poderiam ser relacionados à sociologia política. Ao observar o uso do poder fiscal pela classe dominante, com o intuito de incrementar o seu bem-estar e a sua posição econômica, Mann perpassa assim, pela teoria das elites, o que inclui um conteúdo sociopolítico em seus estudos. Como ressaltado na literatura pertinente, em toda sociedade haverá sempre uma minoria organizada que controlará uma maioria desorganizada (MOSCA, 1896). A partir dessa perspectiva e influenciado, ainda, pelos fundadores italianos da sociologia financeira, Mann (1943, p. 229) enfatiza que «In all periods of history, the ruling class has made use of the taxing power to increase its own welfare and to strengthen its economics position ». De fato, o acesso à riqueza social produzida em parte, pelo próprio Estado, foi possível graças ao uso dos meios legítimos do taxing power pelas classes privilegiadas. Essas tem meios legais de não apenas repercutir o ônus tributários mas também se aproveitarem, mesmo ainda na presente quadra, de regimes fiscais favoráveis. $\mathrm{O}$ domínio do sistema legal se constituiu em um dos objetivos maiores de controle do contexto sociopolítico.

Em consequência, pode-se afirmar, sem receios, que o tributo e o sistema tributário sempre se constituiu em uma arena de disputas políticas. Nesse caso, a busca pela reforço de poder e a disputa pela riqueza social se constituíram em objeto de cobiça das classes em posições políticas privilegiadas. Expondo com muita clareza essa posição, Perissinotto (2009: 29), ressaltou com extrema propriedade que « Uma classe política agirá sempre no vol.09, nº. 04, Rio de Janeiro, 2016. pp. 1841-1864 1846 
sentido de manter o monopólio sobre os recursos socialmente valorizados que lhe possibilitem o domínio político sobre o resto da sociedade ». Esses recursos, à disposição de todos mas de forma escassa, se constituem na riqueza social da qual nos fala Walras (1952, p. 21) em sua abalizada obra sobre economia política, que a definiu como sendo « l'ensemble des choses matérielles ou immatérielles qui sont rares, c'est-à-dire, d'une part, nous sont utiles, et qui, d’autres part, n’existent à notre disposition qu’en quantité limitée ». No entanto, o próprio Walras (1952, p. 34) ressaltaria que no seio da divisão do trabalho, a repartição da riqueza social entre os homens em sociedade deveria ser equânime. Ora, nessa compreensão há um certo resgate do conteúdo funcionalista trabalhado por Mann quando este expõe que entre as necessidade de controle social, se insere aquela voltada ao reajustamento de poder entre grupos sociais e classes. Depara-se, mais uma vez, com outra convergência entre Musgrave e Mann ao se acordar que esse reajustamento seria possível apenas com um eficiente sistema de redistribuição. Seria portanto, uma igualdade pelo tributo.

De forma inegável, pode-se afirmar que o reajustamento de poder remete aos temas caros à sociologia. A mobilidade social e a circulação das elites se tornaram uma espécie de pièce de resistance da sociologia funcionalista. Tocqueville (BENOÎT, 2000, p. 59) pleiteou um Estado social como corolário da democracia, tudo baseado na equalização progressiva das condições, o que levaria à igualdade dos direitos, sendo possível, assim, assegurar a mobilidade social. Bottomore (1964, p. 48) trata sobre a circulação das elites e cita Pareto para afirmar que "History is a graveyard of aristoracies", uma forma de ressaltar a alternância de poder mesmo entre as classes privilegiadas. Aliás, como garantiu Perissinotto (2009, p. 30), "As mudanças sociais estão sempre ligadas a mudanças nas fontes de poder e geram mudanças na classe política”. Verifica-se, portanto, que esse movimento geral das sociedades que por serem heterogêneas, compõem diversos cenários sociopolíticos. Ora, Pareto estabeleceu um novo modelo sociológico que, de acordo com o Genieyes (2011, p. 69), seria o da circulação das elites e que, devido a essa heterogeneidade social, haveria uma mobilidade entre as camadas das elites e, também, entre elite e a massa. É importante insistir que nos dois processos, mobilidade social e circulação das elites, ocorre esse reajustamento de poder entre classes sociais, de maneira especial em razão do processo de equalização promovido pela grande sociedade solidária.

Prosseguindo na lição de Mann, é conveniente observar que o tributo passa a ter duas finalidades distintas, ou seja, para acentuar as desigualdades de riqueza, ou no sentido inverso, para reduzir a distância entre as classes por meio do imposto progressivo. A partir desta constatação é possível estabelecer uma análise mais abrangente do tributo nos domínios da sociologia política em face de que, além de expor duas ideologias opostas - liberalismo e socialdemocracia - o autor remete à questão, mais uma vez, à teoria das elites. Em realidade, apesar do forte conteúdo funcionalista impregnado em suas ideias, Mann (1943, p. 29) admite, como visto acima, o fato de que a classe no poder use o taxing power para reforçar posições. Em consequência das ambiguidades demonstradas quanto ao papel do tributo, nota-se, sem dificuldades, que o sacrifício fiscal sempre foi repartido de vol.09, nº. 04, Rio de Janeiro, 2016. pp. 1841-1864 1847 
forma desigual entre os indivíduos, havendo sempre uma espécie de dirigismo por parte das classes privilegiadas. Na verdade, dependendo do grupo no poder ou da ideologia adotada por determinado governo, o tributo tornase um trunfo significativo na disputa de classes.

Mann, com o intuito de lapidar a sua lição sobre a sociologia fiscal, propõe uma reorientação da mesma ao notar que no contexto do New Deal keynesiano, uma mudança maior foi produzida: o governo passou a assumir cada vez mais funções voltadas para as finanças públicas (com o respectivo crescimento do setor público) e o tributo preencheu então uma função social ao lado de sua função clássica de financiamento do Estado (LEROY, 2010a, p. 52). Em verdade, o keynesianismo viria a reforçar o papel intervencionista do Estado em face da depressão econômica americana e das demais grandes economias ocidentais. Os graves desequilíbrios macroeconômicos verificados naquela ocasião poderiam ser sanados apenas pelo Estado por meio da introdução de mecanismos capazes de estabilizar os mercados. Todavia, para uma melhor compreensão no que se refere à função social do tributo e os seus desdobramentos posteriores, há que se recorrer a um resgate histórico no sentido de ressaltar o seu papel na mudança social ocorrida na sociedade pós-Revolução Industrial. $\mathrm{O}$ desequilíbrio entre o capital e o trabalho em consequência direta das falhas do mercado, levaria à instauração do Estado intervencionista e do Estado providência. Nesse contexto, a passagem do Estado tradicional ao Estado moderno demandaria os meios de financiamento necessários à mudança da paisagem social do Século XIX. O desenvolvimento do Estado-providência, conforme notou Rosanvallon (1985: 07), estava prestes a vencer a velha insegurança e o medo do amanhã. A implantação de uma importante legislação social acompanhada da instauração do imposto progressivo sobre a renda são percebidos nos países da Europa ocidental onde a mudança social ocorreu de forma mais intensa: Alemanha, Inglaterra e França. Trata-se, por conseguinte, de um divisor de águas que permite deduzir que a função social do tributo já se constituía em um consenso no Século XIX. Steinmo (1993, p. 51), se refere a essa passagem do sistema tributário clássico ao moderno, de forma a confirmar a procedência do título de sua importante obra sobre tributação e democracia:

Two intimately interconnected and yet distinct forces appear to have been at work at the end of the nineteenth and beginning of the twentieth centuries, forces that explain the transformation from classical to modern tax systems(...): one supported political and social equality in society, the other demanded increased revenues on the part of the state, and together these two impulses brought about new tax ideas and structures.

Dessa forma, as transformações do Estado e de suas instituições, notadamente no curso da década de setenta do Século XX, deveu-se, em grande parte, ao acirramento do liberalismo e da socialdemocracia, culminado na crise deste último. De fato, o confronto de forças lançou todos nos caminhos da pós-modernidade uma vez que o exaurimento dos argumentos de ambos os lados, levou a uma certa fadiga do debate social, o que impôs a busca por novas alternativas ideológicas, como por exemplo a terceira via de Giddens ou ao socialismo liberal ou associacionista de Hirst, como citado por Audier (2006, p. 103). Finda, talvez, a modernidade inaugurada na sociedade pós-Revolução industrial, esses temas se tornarama recorrentes e passaram a justificar toda a construção vol.09, nº. 04, Rio de Janeiro, 2016. pp. 1841-1864 1848 
teórica em torno da organização da sociedade civil com vistas à atuação do Terceiro Setor. Seria este um dos pressupostos que levarão à pós-modernidade?

Retomando a argumentação proposta no trabalho, faz-se necessário enfatizar que Mann foi um dos primeiros a conceber a necessidade de uma sociologia fiscal funcionalista tendo em vista que os economistas reduziram esta análise a sua dimensão econômica (LEROY, 2010a, p. 52). Desta observação percebe-se que o resgate dos fundamentos da grande sociedade solidária se revelou importante à sociologia funcionalista. Com efeito, a coesão social seria indispensável à harmonia da vida coletiva. Mann evoluiu nas suas ideias a partir desse viés funcionalista, realizando uma conexão entre os meios de sustentação da ordem social e da atividade financeira do Estado. Não obstante esse encadeamento, um único reparo a ser feito na análise funcional do pensador alemão seria o fato de que, como exposto anteriormente, o tributo já era uma fato social importante na mudança dos séculos. A consagração do keynesianismo viria apenas a reforçar esse papel. Os princípios basilares da tributação moderna (capacidade contributiva e consentimento) consagrados nos artigos 13 e 14 da Declaração Universal dos Direitos do Homem e do Cidadão de 1789, e decorrentes de uma revolução política validariam, mais tarde, o tributo como o motor da coesão social na sociedade pós-Revolução Industrial. Conforme assinalou Parsons (1973, p. 78), ao se referir à « revolução industrial » e à « revolução democrática », iniciadas na Grã-Bretanha e na França, em um cenário influenciado por duas revoluções, formou-se uma cultura de sociedades em mudança, dando início ao processo social do Século XIX, o qual projetou as bases da sociedade industrial e dos conflitos próprios de uma nova paisagem social. Infere-se, então, que desses dois movimentos, vieram as ideias e pressupostos que levaram à passagem da sociedade tradicional à sociedade industrial e, em última instância, à mudança social responsável pelo florescimento da sociologia.

A partir desta confluência de fatos sociais foi possível esboçar uma teoria normativa do Estado como esforço para se analisar as justificativas para a intervenção pública como reiteraram Bozio e Grenet (2010, p. 08) e, inclusive, uma justificativa econômica e social nos moldes preconizados por Marchand (1999, p. 08). Esse último observa que o Estado, por deter o monopólio da coação legal, exercida por meio do tributo ou da regulamentação, detém, igualmente, os mecanismos da redistribuição pública. Da confluência das ideias tratadas acima, depreendese que a própria sociologia fiscal e a sociologia financeira (não abordada nesse trabalho) se encarregaram de estabelecer o amálgama entre as variantes que compõem a atividade financeira do Estado. Apesar da constatação de que a atividade estatal transcorre em um cenário de conflitos, às vezes ideológico ou doutrinário, a coesão social permanece, todavia, como um dogma a ser acatado.

\section{O CONTROLE SOCIAL NA LÓGICA FUNCIONALISTA}

Nas lições da sociologia funcionalista é cediço que a sociedade é superior ao indivíduo que nela vive. Ao 
dar origem à sociedade, o homem contribui na mesma intensidade para a criação de instituições sociais as quais passaram a condicioná-lo por meio da imposição de regras de conduta. As formas de agir do indivíduo, nesse caso, provêm da sociedade e são, por isso, exteriores e coercitivas a ele. Tendo por escopo o fato social, a sociologia funcionalista procurou demonstrar as funções que eles exercem por meio de investigação realizadas a partir da observação das práticas sociais. Por isso, a sociedade é semelhante a um corpo vivo, formado por várias partes nas quais cada um cumpre a sua finalidade. Assim, podem ser elencadas as organizações sociais como a família, a religião, a instrução, além de inúmeras outras formas sociais. Em suma, a sociedade é um conjunto de normas onde prevalece o controle social sendo a punição o corolário de um direito repressivo. A violação das regras se traduz em ameaça à coesão social e à solidariedade. Esses propósitos integram a solidariedade mecânica de Durkheim e são os valores do consciente coletivo comum que consagra o entendimento de que os transgressores serão punidos como exemplo para demais membros do corpo social.

Por sua vez, a solidariedade orgânica, calcada na divisão do trabalho social, prega um direito restitutivo no qual a função da lei e da sanção é o de restabelecer a ordem social. A arquitetura social esboçada por Durkheim, onde o indivíduo passa a depender do outro, leva inexoravelmente à noção da grande sociedade solidária. Todos tem o seu o seu papel na sociedade o que gera, por um lado, uma cadeia de dependência e, pelo outro, as desigualdades sociais. Influenciado pela mudança social operada na sociedade pós-Revolução Industrial, Durkheim pôde construir suas ideias a partir de indagações sobre a evolução das sociedades modernas baseadas nas diferentes funções sociais, justificando a partir daí, a integração dos indivíduos em sociedade. Isso posto, Durkheim (2014) estabeleceu os fundamentos de sua teoria social com base na norma e na sanção como suportes indispensáveis à vida em sociedade.

Por isso, a coesão funcional não seria jamais alcançada sem uma sociedade bem organizada e capaz de permitir a realização das funções sociais que lhes são próprias. Porém, há que se ressaltar que o equilíbrio social e a legitimação do fato social como indutor da conduta individual seria obtido apenas a partir da coerção. Nessa inteligência, os quatro elementos do controle social, conforme a enumeração de Castro (1999, p. 90), valor, norma, vontade e ação, orientariam as condutas sociais, no universo positivo, no sentido de garantir a coesão social pois a punição se consistiria na única forma de se manter a ordem social. É possível notar, portanto, que esses elementos conduzem a Mannheim (1971, p. 178), segundo o qual "conjunto de métodos pelos quais a sociedade influencia o comportamento humano, tendo em vista manter determinada ordem”. Bottomore (1987, p. 199), em sua antológica obra sobre sociologia, ao formular o seu conceito sobre o controle social observou sobre os valores e normas incidentes sobre o corpo social:

A regulação do comportamento na sociedade, quer por indivíduos ou por grupos, é empreendida de duas formas: pelo uso da força e pelo estabelecimento de valores e normas que podem ser aceitos mais ou menos integralmente pelos membros da sociedade como « normas de conduta $»$ obrigatórias. 
O controle social seria, pois, esta segunda definição a qual teria a eficácia de minorar as tensões e conflitos entre indivíduos e grupos a fim de manter a solidariedade (BOTTOMORE, 1987, p. 199). Por conseguinte, a solidariedade coercitiva decorreria da evolução social. De fato, a implicação de todos no processo de construção de uma nova sociedade não poderia deixar margem a decisões mais racionais, discricionárias ou subjetivas no que se refere ao alcance da eficiência coletiva. Donzelot (1994, p. 83) aduz que a teoria da solidariedade permite afiançar que a sociedade vive e evolui segundo leis próprias. Seria essas, portanto, as premissas que levaram à constituição de uma solidariedade social esboçada nos intramuros do Estado intervencionista. Ao estabelecer uma forma de comportamento do corpo social voltado para a solidariedade coercitiva, o intervencionismo estatal deu início a um processo de positivação de direitos sociais com vistas ao reconhecimento do individualismo e dos valores democráticos. Tocqueville já havia realçado a importância de uma sociedade democrática que garantisse a igualdade de condições, pressupostos que afirmariam a necessidade de um estado social e não apenas político (BENOÎT, 2000, p. 59). Esses eram os valores da socialdemocracia ao final do Século XIX e que se sobrepuseram aos valores do liberalismo, desgastados pelas falhas do mercado. Com suas contradições, as promessas de liberdade da socialdemocracia sofreriam um duro ataque da intelligentsia liberal por todo o Século XX.

A partir dessas avaliações é possível afirmar que este arcabouço de ideias assentaria de vez o sonho da solidariedade. A perenidade destas ideias como trunfo indissociável da mudança social da sociedade pósRevolução Industrial permaneceria incólume, apesar dos reparos realizados na Inglaterra beveridigiana após o fim da Segunda Guerra mundial, até a grande crise do Estado providência nos estertores do conturbado Século XX.

Instaurada a grande sociedade solidária durkheimiana com a sua estrutura calcada na divisão do trabalho social, o coletivo se organizaria em um escala vertical, o que daria origem às desigualdades sociais na era pósRevolução Industrial. Contudo, estas não seriam pensadas por Marx, as quais se formariam a partir da posse dos meios de produção e da propriedade. Em realidade, tratava-se de uma sociedade segmentada pela divisão do trabalho social, esteada em uma solidariedade mecânica onde todos teriam o seu papel. Aron (1962, p. 18), se referiu a essas diversidades sociais colocadas no interior de cada coletividade e que seriam, de fato, as sociedades polisegmentadas conforme a lição de Durkheim.

A esses eventos da sociedade pós-Revolução Industrial devem-se juntar os princípios incorporados pela revolução política - a Revolução Francesa - onde foi possível introduzir as diretrizes da tributação moderna: a capacidade contributiva e o consentimento ao tributo, ambos surgidos da pluma de Rousseau. Assim, em face de sua sustentação política, o imposto progressivo se tornaria, nas palavras de Rosanvallon (2011, p. 227), um possível instrumento de reforma social na sociedade do final do Século XIX. Desse fato, ainda nas palavras do mesmo autor (2011, p. 232), «Le bouleversement a été autant intellectuel que social ou politique $\gg$. Em realidade, a mudança social do Século XIX viria acompanhada da necessidade de financiamento da solidariedade coercitiva implantada pelo novo Estado social, sendo esse uma significativa área de atuação da sociologia fiscal. vol.09, nº. 04, Rio de Janeiro, 2016. pp. 1841-1864 1851 
Em consequência, a efetivação de um controle social seria o desdobramento natural do processo de passagem da sociedade antiga à moderna. A legitimação do poder tributante do Estado, por meio do consentimento de todos, noção esta estreitamente vinculada à nova dimensão da democracia, era o preço a ser pago e que, além possuir traços contratualistas abarcava ainda a teoria normativa do Estado. O fato é que o sacrifício fiscal se constituiria em um importante meio de coesão social e, como asseverado, implicaria todos no consenso destinado a promover uma sociedade melhor.

De forma incontestável, ao se integrar ao debate em curso, o tributo se tornaria um fato social imprescindível para o progresso das sociedades. Nessa mesma lógica, Bouvier (1996, p. 113) acrescentou que o tributo se constituiria também em um fato político, econômico, administrativo e ideológico. Essa dimensão normativa do tributo se revelaria o pomo de discórdia entre a vertente liberal e socialdemocrata. Ao contrário do que afirmou Rosanvallon, nas fileiras liberais o inconformismo com essa forma de redistribuição da riqueza social viria a ser contestada vigorosamente, já no Século XX, por Hayek em seu incansável discurso antikeynesianista. O economista austríaco reiterou que a tributação progressiva seria «uma espoliação ilegítima das rendas de um grupo que contribui de forma potencial ao crescimento econômico e ao progresso da civilização », consistindo, assim, em uma rejeição impregnada de forte conteúdo liberal, fato esse ressaltado por Dostaler (2001, p. 77).

É importante observar, pois, que o binômio tributação e solidariedade viria a se tornar um valioso meio de controle social. A sociedade solidária, destinada a responder aos anseios de liberdade, de democracia e de mobilidade social, se constituía em umconsenso firmado com supedâneo na legislação social e nas instituições que compunham a paisagem social do Século XIX. Ao justificar as duas modalidades de representação que permeiam o tributo desde a sua origem, a submissão e meio de solidariedade do grupo social, Bouvier (1996, p. 199) resgatou, por um lado, o fundamento antropológico do sacrifício fiscal ao preconizar que o homem seria um eterno devedor do invisível e os fundamentos das sociedades seriam anterior ao próprio Estado. Na segunda perspectiva, o tributo como meio de solidariedade do grupo social, o autor (1996, p. 199) apontou, de forma categórica, as justificativas para a legitimação do tributo:

Cest en effet grâce à elle que limpôt a pu se présenter comme expression et condition nécéssaire de la solidarité et du lien fiscal, comme le moyen privilégié de la cohésion, de l'intégration de la communauté, puis de la nation et de l'État.

Dessa manifestação depreende-se, então, que o tributo se colocou como o meio necessário à vida em sociedade, se constituindo em traço importante da coesão social e da integração comunitária segundo os ditames da sociologia funcionalista. Em síntese, o movimento social do final do Século XIX seria responsável, no século seguinte, pela onda constitucional que viria a sustentar a democracia, observando a contribuição das constituições do México de 1917 e a de Weimar de 1919. As contradições decorrentes do intervencionismo estatal, como observado anteriormente, suscitaram um controverso debate. Pelo menos a ordem social estaria preservada do fogo cerrado liberal até o fim dos Trinta Gloriosos. A positivação dos direitos sociais se tornaria, em decorrência 
da mudança social, uma vitória inicial do proletariado. Entretanto, Marx enxergou naquela paisagem social, o início de uma nova disputa de classes. Qual seria então o instrumento capaz de garantir a perenidade dos direitos recém-adquiridos? Apesar dessas clivagens, Bottomore (1987, p. 241) teve uma visão mais otimista do papel do direito na consolidação da ordem social sem negligenciar o fato de que tudo decorreria de um modo de vida criado por doutrinas morais e políticas.

De forma definitiva, pode-se firmar o entendimento de que Bottomore justificou a primazia de um sistema de direitos e cuja argumentação em torno do objeto pode ser exposta às divisões ideológicas registradas na sociedade pós-Revolução Industrial. A controvérsia instalada entre liberais e socialdemocratas expunha claramente os campos opostos em que se colocaram essas ideologias. O predomínio desta última, com a expressa permissão do intervencionismo estatal, tornou possível consolidar a ordem social emergente. No resgate antropológico do dever de pagar tributos, a submissão ou o sentimento de preocupação com o bem-estar do próximo forjou os valores morais que levariam à formação de uma sociedade justa.

Entretanto, em sua dimensão política, o tributo obteve legitimidade ao se constituir em um dos traços característicos do Estado moderno e democrata. O princípio do consentimento viria a conferir essa legitimidade. A consolidação de uma nova ordem social positivada, tornou-se, assim, o elo de ligação entre a coesão social e a necessidade de um controle social uma vez que o Estado havia arvorado para si, o monopólio da coerção legal. A solidariedade deixou de ser um valor apenas ético e moral para se constituir em valor compulsório na nova paisagem social. Foi essa a junção reclamada por Bottomore.

Não obstante as origens do tributo estarem ligadas à violência e à submissão, decorrentes, dentre outros, dos valores religiosos nos quais o homem sempre seria um eterno devedor do invisível, o ônus fiscal tornou-se um símbolo da evolução democrática. Nessa argumentação, a noção de dívida seria um elemento fundamental do funcionamento e até mesmo da evolução das sociedades (BOUVIER, 1996, p. 118), o que validaria o controle social.

Por isso, mesmo que esses valores tenham se constituído nos alicerces da sociedade solidária, havia a necessidade do estabelecimento de uma norma com vistas a possibilitar ao Estado intervencionista, o controle social efetivo dos valores antes restritos à concepção naturalista. Heer (1937: 484) admitiu que «However reluctant we may be to admit it, taxation inevetably is an instrument of social control $\gg$. Em realidade, o tema tem passado desapercebido na literatura recente. Todavia, a primeira metade do Século XX seria pródiga na consolidação do entendimento nos meios acadêmicos de que o tributo seria também um meio de controle social. Como se verá mais adiante, Mann contribuiria com a matéria ao extrapolar a visão econômica do tributo de Musgrave. Entretanto, seria Heer (1937, p. 484), em seu pioneiro trabalho, quem lançaria uma luz sobre a questão ao reiterar o papel importante do controle social em face da mudança econômica e social: 
Since all taxes inevitably produce social and economic changes, the question at issue is not whether taxation should be used as an instrument of social control but how it mai be used more intelligently to achieve consciously sought social objectives.

\section{AS TRÊS FUNÇÕES DO CONTROLE SOCIAL NA LÓGICA FUNCIONALISTA DE MANN}

Se Musgrave codificou as funções econômicas do tributo, Mann remeteu a questão ao plano social, imprimindo-lhe valores funcionalistas e o levou a propor as funções de controle social com supedâneo na realidade fática observada. Em verdade, haveria um ponto em comum entre as duas percepções do ônus fiscal. O Estado define determinadas condutas sociais desejadas a partir da influência que exerce sobre o comportamento dos indivíduos. A partir dessa perspectiva, é que se pode compreender melhor o objetivo de Mann ao estabelecer um liame entre o tributo e o controle social, instituto próprio das sociedades organizadas.

$\mathrm{Na}$ verdade, a noção de controle social é estreitamente relacionada à necessidade de se coibir transgressões às normas estabelecidas por um determinado sistema social. A partir de um poder político capaz de ditar normas, a sociedade se constitui em um todo harmônico onde a sanção tem o papel fundamental de assegurar a estrita obediência de todos às injunções de ordem legal. Desse modo, o cumprimento dessas normas garantiria a harmonia social e a obtenção da eficiência alocativa. Dessa constatação, emerge o consenso sobre a importância do tributo como forma de coesão social e de alicerce da grande sociedade solidária cuja arquitetura foi delineada a partir da Revolução Industrial. Todo esse contexto valida o esforço de Mann em modelar um estereótipo do tributo como forma de controle social. Com efeito, o mesmo se constitui em uma espécie coercitiva de solidariedade não havendo, por isso, como pensar em uma sociedade sem tributo.

\section{A primeira função do controle social de Mann: a correção de comportamentos não desejados}

Mann (1943, p. 226) observou que «Since, by alternating the bitter with the sweet, political authorities can exercise a strong power of persuasion, it is not suprising that, at least occasionally, taxation has functioned as al tool of collective education », o que assenta os fundamentos da primeira função de controle social. Essa definição permite uma melhor compreensão de todo o comportamento do Estado que, por meio de sua política fiscal, exterioriza as suas estratégias com vistas à orientação do comportamento social e do mercado.

A regulação da economia, o incentivo à adoção de condutas pautadas nas normas de saúde pública ou de questões ambientais, por exemplo, e os regimes tributários incidentes sobre o núcleo familiar se inserem na perspectiva desta modalidade de controle social. Em um exame mais detalhado do cenário fiscal contemporâneo é possível evidenciar a visão até certo ponto premonitória de Mann sobre esta função do controle social. 
Deve-se tomar como exemplo o fato de que em diversos sistemas tributários, a imposição do núcleo familiar se tornou um dos componentes importantes da política fiscal. O papel da família na sociedade, como ressaltado por Leroy (2010b, p. 143), sempre foi objeto de importante estudo pela sociologia e por outras ciências sociais como a antropologia, a história, a demografia, a economia, a ciência política e, também, pelo direito. Beltrame (2010, p. 19), ao estabelecer um liame entre tributo e família, observou com pertinência o fato de que o tema pode suscitar debates apaixonados:

Famille... Impôt... Même pris séparément ces deux mots évoquent des institutions essentielles, séculaires et controversées. Considérées dans leurs relations réciproques, elles ne peuvent que susciter des débats passionnés. En effet, la famille et l'impôt touchent aux ressorts intimes et fondamentaux de la nature humaine : l'être et l'avoir, ce qui peut les conduire à s'opposer.

Nesse sentido, a penalização daqueles que optaram pelo celibato é evidenciada, no sistema progressivo de tributação da renda, por uma carga mais elevada, por exemplo. Trata-se, portanto, de uma forma de induzir comportamentos em torno de um componente social importante. O tratamento tributário dispensado a famílias numerosos encontra uma justificativa, por exemplo, nos problemas demográficos conhecidos em inúmeros países. Nesse caso, diversas modalidades de incentivos fiscais são colocados à disposição com o intuito de orientar estratégias e atenuar problemas sociais. A adoção do « quociente familiar » em determinados sistemas tributários por exemplo, tem confirmado o acerto desta política como um meio ótimo de controle social ao induzir mudança de comportamentos.

Por outro lado, no plano econômico, a intervenção com o intuito de introduzir estabilizadores macroeconômicos destina-se a reduzir desequilíbrios, tornou-se uma ferramenta primordial das economias modernas. O efeito do tributo sobre os agregados macroeconômicos tais como os níveis de produção industrial, de emprego, de consumo e de inflação o coloca em posição privilegiada na condução não apenas da política fiscal mas, também, da política monetária. Com a ocorrência de crises econômicas pode-se perceber que incentivos fiscais são adotados com o objetivo de estimular o consumo de determinados bens e, dessa forma, salvar empregos e indústrias. Os governos podem, em consequência, modificar as opções de consumo, de produção e de investimentos dos indivíduos. Todavia, tal medida tem um impacto direto sobre a neutralidade do tributo nos circuitos econômicos. De acordo com a teoria do tributo, esse deveria ser neutro e não incidir sobre qualquer uma das decisões dos indivíduos. Contudo, a primazia do interesse coletivo sobre o particular, na ótica do poder político, justificaria esta conduta e sobretudo por ela decorrer de uma função primordial do Estado, a de garantir a harmonia sociopolítica.

Assim é que o uso reiterado da extrafiscalidade se insere, de forma permanente, na paisagem fiscal contemporânea. Nessa hipótese, o Estado utiliza o tributo para alcançar determinados comportamentos nos mais diversos segmentos da vida em sociedade, como mencionado há pouco. Ao acompanhar de perto o consumo de produtos considerados nocivos à saúde pública, o Estado busca preservar também valores relacionados à ordem vol.09, nº. 04, Rio de Janeiro, 2016.pp. 1841-1864 1855 
social. Esta tem sido a conduta em sistemas tributários modernos e melhor estruturados com vistas à otimização do controle social. A margem de manobra que estes possuem permite um maior deslocamento do foco tributário, alcançando resultados que contribuem significativamente para o equilíbrio do binômio equidade-eficiência. Ao impor um ônus tributário mais pesado ao consumo de produtos considerados como geradores de externalidades negativas, o Estado atribui condutas consideradas mais próximas do interesse coletivo. Na esfera da justiça fiscal, com o escopo de atenuar o caráter regressivo dos tributos indiretos, o Estado manipula as alíquotas ao estipular percentuais mais baixos para produtos considerados essenciais para os indivíduos pertencentes às classes menos favorecidas e estabelece percentuais mais elevados para produtos do segmento de luxo. Na seara ambiental, o princípio do poluidor-pagador vem ganhando dimensões importantes em decorrência da necessidade de se impor aos indivíduos, um ônus pela externalidade negativas que estes geram. Deve se observar que esse tema vem ganhando na atualidade, uma dimensão considerável em face do debate sobre a questão ambiental. De forma indiscutivel, trata-se de um excelente utensilio de controle social.

De forma inequívoca, é importante retomar a ideia de que Mann emprestou uma nova dimensão às funções clássicas do tributo, antevendo em sua época e com muita precisão, que o tributo se constituiria em um meio pelo qual o Estado poderia se localizar melhor no seu universo normativo.

\section{A segunda função do controle social e as perspectivas antagônicas do tributo: o reajuste do poder econômico entre os grupos sociais e a redistribuição vertical}

Embora Mann tenha insistido no fato de que o tributo permitiria o reajustamento do poder econômico entre os grupos sociais, é importante ressaltar o papel da redistribuição nesse processo. Porém, sempre houve uma disputa latente pela riqueza social, o que confirmou, inclusive, a pregação marxista segundo a qual, a mudança social levaria a uma nova luta de classes. O reajuste do poder entre as classes ocorreu, justamente, no acesso privilegiado que parte dessas teriam ao aparato estatal ou, de outra forma, ao sistema legal como resultado da vontade de uma minoria. A organização de forças sociais em torno do Estado resultaria em um processo de estratificação social que teve em Tocqueville um importante precursor, quando esse pregava a igualdade de condições como meio de mobilidade social. Entretanto, seria nos domínios da teoria das elites esboçada por Mosca e Pareto que se teria a explicação para a apropriação do processo político pela minoria organizada em detrimento de uma maioria desorganizada. Em realidade, tudo decorreu de um complexo cenário sociopolítico formado pelos movimentos sociais e pela elite os quais buscavam, de maneira incessante, os meios de apropriação da riqueza social.

Não obstante o fato de que a produção de um importante debate sobre a democracia e justiça social, ao tempo da sociedade pós-Revolução Industrial, vir acompanhado da instauração da tributação progressiva e do 
consenso social, o sistema tributário se constituiria em uma arena de disputa política, jogando por terra, ainda que de forma parcial, os ideais da grande sociedade solidária. Como ressaltado, Mann destacou a utilização do taxing power como forma de reforçar posições econômicas. Ao se lançar um olhar sobre as formas primitivas de tributação até os modelos estereotipados como modernos, verificar-se-á, sem dificuldades, que o fardo fiscal serviu de justificativa para revoluções, relações de domínio e de espoliação social. De fato, ao atribuir uma função de controle social com vistas ao reajuste do poder econômico entre classes sociais, Mann adentrou na intimidade da teoria do tributo como meio definitivo para favorecer o equilíbrio social. A igualdade pelo imposto e diante do imposto se tornou o dogma dos construtores do solidarismo social. O reajuste de poder entre classes sociais ocorreria em um processo marcado pela verticalidade, onde a redistribuição vinda de cima permitiria o equilíbrio social ao alçar aqueles que se encontravam na precariedade, ao equilíbrio social localizado no ponto médio da escala. A circulação social se constituiria, assim, em uma decorrência natural da tão almejada igualdade de condições idealizada por Tocqueville.

Embora tenha permitido a ascensão do proletariado, o processo ocorreu no sentido de reforçar o poder da minoria organizada, a qual passou a ter um maior acesso à riqueza social. Os discursos sobre as desigualdades, em voga nas sociedades atuais, decorrem no caso em comento, da ação privilegiada de grupos detentores dos meios de produção, da propriedade e, ainda, da divisão do trabalho social. Essa seria a característica maior das sociedades diferenciadas. Os recursos socialmente valorizados numa dada sociedade sempre são escassos e por isso controlados por alguns poucos (PERISSINOTTO, 2009, p. 43). Portanto, esse é o lócus de toda a disputa social. Esse pressuposto serviu de pretexto para a ferocidade com que os liberais defendiam as suas ideias, tendo reunido um notável acervo de justificativas para a lógica capitalista e edificaram, com isso, as bases de uma nova teoria normativa para o intervencionismo estatal. À solidez do discurso liberal se juntaram não apenas as lições dos italianos Mosca e Pareto, adeptos do elitismo, mas também a renovação teórica ocorrida na América, conduzida por Wright Mills em sua obra sobre a elite do poder, na primeira metade do Século XX. Essa espécie de ação conjunta concorreria para a afirmação da primazia sociopolítica usufruída pela minoria organizada que só viria, cada vez mais, ver o seu raio de poder consolidado. A tímida reação do meio sindical, ao longo de todo o século, alternou momentos de plenitude política com o avanço dos Estados sociais no pós-guerra e de declínio a partir do fim dos Trinta Gloriosos. Prevaleceu, enfim, a lição de que o outro lado seria o mais capacitado para organizar a democracia e o sistema produtivo. Meynaud (1960, p. 05), em alentado estudo sobre os grupos de dominação, firmou que estes lutam de forma engajada com vistas a tornar as decisões dos poderes públicos de acordo com os interesses ou ideias de uma determinada categoria social e, por isso, são considerados como um instrumento poderoso de anulação da democracia. Retomando ao ministério de Aron (1962, p. 278), em suas antológicas lições sobre a sociedade industrial, proferidas nos anos cinquenta do Século XX, na Universidade de Sorbonne, foi exposto que a teoria de James Burham sintetiza a concepção marxista e paretiana acerca das classes: cada classe vol.09, no. 04, Rio de Janeiro, 2016. pp. 1841-1864 1857 
dirigente, sem ser necessariamente homogênea, seria caracterizada pela predominância de um grupo ou de um tipo de homens. Do profícuo aprendizado trazido por Meynaud e Aron emerge a indagação sobre se efetivamente seria possível o reajuste de poder defendido por Mann.

Ao pregar a necessidade de reajustamento de poder, Mann talvez tenha demonstrado certa decepção com o mecanismo fiscal. Haveria, efetivamente, um deslocamento de poder em razão da política fiscal e da estratégia dos gastos públicos, o que proporcionaria em consequência uma maior justiça social? Bottomore (1964, p. 339), em acertado diagnóstico, desconstrói o processo de redistribuição em face de uma elite organizada. Nessa medida enfatizou que « on the other side we must note that the decline in the proportion of private wealth owned by the upper class has been modest and very slow, and that the redistribution of income through taxation has not proceeded very far ». Hayek se alinha a esta aversão ao tributo como forma de redistribuição e que se pare de utilizá-lo como meio de redistribuição e como alavanca da política econômica (DOSTALER, 2001, p. 78).

Apesar do fato de que a intervenção do Estado encontra seus fundamentos teóricos na abordagem normativa, Bozio e Grenet (2010, p. 31), observam, em consonância plena com Meynaud, que uma miríade de outros atores buscam modificar a ação do Estado para obterem benefícios pessoais. Dessa inteligência é possível depreender que a disputa pela riqueza social, a partir do sistema tributário e das políticas públicas de redistribuição é, de longe, o meio de reajustamento de poder entre as classes organizadas. Mann (1943, p. 229) já havia arrematado nessa direção ao falar sobre o reforço do poder do ruling class a partir do poder tributante.

O reajustamento do poder econômico entre as classes por meio do tributo permaneceria, então, limitado enquanto forma de controle social em face do apelo político da minoria organizada. Que argumentos restariam a Mann diante de tão elaborada construção teórica? Talvez Aron ou Pareto pudessem fornecer a resposta uma vez que as suas obras fazem uma constante referência ao século das luzes e aos seu conflitos, ao desequilíbrio entre o capital e trabalho, à mobilidade social e à circulação das elites. Todavia, na análise de Leroy, o tributo atuaria em sentidos opostos. De um lado, poderia acentuar as desigualdades produzidas pela riqueza. Pelo outro, seria aplicado para reduzir a distância entre classes sociais por meio do imposto progressivo. A percepção por Leroy desse paradoxo se encontra, aliás, diante do dilema que sempre permeou a condução da política fiscal, no contexto de uma abordagem mais pragmática. Em realidade, a convivência entre um valor e o outro se constituiu, desde sempre, em fato imutável de nossas sociedades. 


\section{A luta contra os abusos sociais do capitalismo e a consequente transição a uma outra ordem econômica: a abordagem utópica de Mann nos tempos da expansão do intervencionismo estatal}

A transposição dos séculos iria demonstrar o equívoco de Mann ao vislumbrar uma outra ordem econômica capaz de se contrapor ao capitalismo. O controle social por meio do tributo, nessa perspectiva, se daria no sentido de consolidar o modelo do solidarismo, da redistribuição vertical a partir, sobretudo, da progressividade. Ao final da primeira metade do Século XX, Mann, talvez influenciado pela expansão sem fronteiras do modelo beveridigiano de assistência universal, surgido na Inglaterra trabalhista do pós-guerra, construiu o seu tripé do controle social a partir do tributo, acreditando que o novo paradigma social seria irreversível. Contudo, no lado oposto da ideologia socialdemocrata, uma luta incessante seria iniciada com o intuito de se contrapor aos excessos intervencionistas do Estado. O combate liberal às ideias construídas a partir do solidarismo se tornaria o motor da pregação dos adeptos do Mont-Pélérin e que triunfariam ao final dos Trinta Gloriosos. A expectativa de uma nova ordem econômica seria contrariada pelos rumos tomados pelo Estado no final dos anos setenta do Século XX. A crise do Estado-providência, como assinalado por Rosanvallon (1997, p. 17), ocorria em parte, devido ao ritmo de crescimento das despesas públicas aliadas a políticas sociais e aos mecanismos de redistribuição serem mais rápidos que o da produção nacional. Para o cientista social, a questão deveria então ser abordada, prioritariamente, em termos sociológicos e políticos (1994, p. 13).

Os supostos abusos sociais do capitalismo, registrados desde a mudança social do Século XX, foram apontados a partir das falhas do mercado e considerados responsáveis pelo desequilíbrio entre o capital e o trabalho. A emergência da socialdemocracia se constituiu em um contraponto importante, em um primeiro momento, para depois se tornar um peso para as Finanças Públicas dos estados ao final do Século XX. Tudo se constituiria em falsas promessas de liberdade e "em relação ao socialismo aquilo que nos prometiam como o caminho da liberdade era na realidade o caminho da servidão." (HAYEK, 2010, p. 49). Todavia, o desenrolar do Século XX evidenciaria as idas e vindas dos discursos liberal e socialdemocrata, expondo em diferentes momentos, clivagens estreitamente ligadas aos eventos que se sucederam como o Manifesto de Eisenach materializado na República de Weimar, o keynesianismo, a expansão do Welfare State e a crise econômica internacional dos anos setenta. Todos esses fatos consolidaram a controvérsia ideológica em torno do capitalismo, vindo esse a prevalecer em decorrência de um sólido estoque de ideias que o tempo se encarregou de provar. Mises (2013, p. 39) defendeu que «A tão falada dureza do capitalismo consiste no fato de ele tratar cada um de acordo com a contribuição que este oferece ao bem-estar do seu semelhante ». Essa foi a resposta dada aos anticapitalistas. O período que se sucedeu à mencionada crise dos anos setenta trouxe a discussão sobre o novo papel do Estado. Além disso, foi marcado pelo ocaso abrupto das garantias sociais, sendo que a partir daí, as economias ocidentais 
se voltaram para as propostas do neoliberalismo para mais tarde se enveredarem na pós-modernidade. Da agenda sociopolítica surgiram novas propostas como a Terceira Via, o Socialismo Liberal e o Socialismo Cooperativo.

Retomando a ideia de Mann acerca do tributo como forma de controle social e a busca por uma nova ordem econômica, cabe destacar que apesar de sua contestação nos dias atuais, a sua contribuição não pode ser negligenciada principalmente quando se lança um olhar sobre a transição social ocorrida na passagem do Século XIX para o Século XX. A percepção do Estado garantidor do progresso da sociedade (DONZELOT, 1994, p. 122) se materializaria a partir da produção de um direito social voltado ao intervencionismo que, por sua vez, tinha o tributo como a sua pedra angular. A coesão social que poderia mudar a ordem das coisas se impôs de forma ostensiva e como decorrência natural do processo.

Durkheim, na esteira da mudança social, contribuiria à afirmação da sociologia como disciplina, tendo proposto um «plano de consistência especifica do social, com as noções de solidariedade e de anomia » (DONZELOT, 1994, p. 76). A implicação de todos no processo social criou a grande sociedade solidária financiada pelo tributo, ou melhor, pela participação da sociedade com vistas a alcançar o bem-estar comum. Infere-se, então, que o controle social surge com o intuito de observar se a conduta do corpo social se passava dentro dos perímetros definidos pelo direito social. Ocorria, assim, a marcha por uma ordem econômica fundada na solidariedade uma vez que a redistribuição seria o elemento propulsor de uma nova sociedade. $\mathrm{O}$ deslocamento ainda que pequeno, de parcelas da riqueza social, mudaria a paisagem sociopolítica do novo século. Conforme observou Rosanvallon (2011, p. 227), a revolução da redistribuição decorreu de três grandes reformas que foram o vetor da passagem de uma estrutura social a outra. A instituição do imposto sobre a renda, a criação de mecanismos de seguridade social e a regulação coletiva do trabalho imporiam, de vez, um novo cenário à relação conflituosa entre o capital e o trabalho. Nesse caso, o imposto seria um instrumento de reforma social e a única forma de se promover uma redistribuição entre classes ou, como ressaltou Leroy (2010a, p. 51), para « reduzir a distância econômica entre as classes ». Torna-se importante notar que esse contexto fiscal já havia sido ressaltado à época da revolução política de 1789, sob a inspiração de Rousseau. Assim, surgiu o viés político que arremataria, de uma vez por todas, os contornos da democracia fiscal destinada a sustentar o progresso social gestado nas sociedades industriais. Todos esses argumentos se revelariam transcendentais para a convicção de Mann acerca de uma sociologia fiscal funcionalista. Na sociedade pós-Revolução Industrial, o estereótipo da solidariedade orgânica e da divisão do trabalho social de Durkheim viria a supor uma espécie de controle formal. A definição do papel de cada um na sociedade implicaria, de forma concomitante, em um dever de ordem fiscal.

Este seria, portanto, o amortecedor destinado a atenuar os ímpetos liberais e criar uma espécie de equilíbrio social. Por mais que se critique o solidarismo com argumentos em princípio, incontestáveis, esse teve o condão de mudar a paisagem social e aplacar, mesmo que em parte, as agruras da lógica capitalista. Embora a consagração do Estado intervencionista fosse responsável por uma nova estrutura do Estado e de suas instituições, vol.09, nº. 04, Rio de Janeiro, 2016. pp. 1841-1864 1860 
a interação entre este e o mercado ocorreu de modo que um passou a depender do outro. Seria então a passagem de uma ordem econômica a outra? Não há como afirmar categoricamente a ocorrência dessa espécie de metamorfose sociopolítica. Em realidade, o que acabou ocorrendo foi uma espécie de mitigação entre uma ideologia e outra, em um exacerbado pragmatismo que permitiu a sobrevivência dos acquis sociaux por mais de um século. A transição para uma outra ordem econômica não ocorreu como se pretendia inicialmente. Todavia, a consagração do Estado intervencionista responsável por uma nova estrutura do Estado e de suas instituições promoveu uma interação entre este e o mercado de modo que um passou a depender do outro.

\section{CONCLUSÃO}

O esforço desprendido ao longo desse trabalho foi no sentido de construir um entendimento em torno do tributo enquanto variável sociopolítica na lição de Fritz Karl Mann. O cientista social vislumbrou uma função para o tributo além da sua concepção clássica de simples carreador de recursos para os cofres públicos, uma nova frente de pesquisa passou a ser desenvolvida nos meios acadêmicos. A notável contribuição desta plêiade de cientistas sociais teve o mérito de estabelecer um liame entre a sociologia e o tributo, tirando-o do seu campo limitado de estudo, restrito quase sempre ao direito, para alçá-lo a outros domínios de compreensão da vida em sociedade. Mann alargou a compreensão do ônus tributário ao atribuir-lhe uma função sociopolítica a qual viria acompanhada das funções de controle social. A correção de comportamentos sociais indesejáveis, o reajustamento do poder econômico entre grupos sociais e classes e, finalmente, o combate aos abusos sociais do capitalismo e a transição a uma outra ordem econômica se constituíram em ferramentas do controle social pelo tributo. Além desse conteúdo sociopolítico significativo, o esforço de Mann contribuiu para a convergência do tributo à lógica funcionalista, permitindo assim a perenidade da ordem social instaurada nas sociedades industriais. Em definitivo, uma pedra foi assentada no percurso desse imprescindível instrumento de organização da vida em sociedade.

\section{TAX AND SOCIAL CONTROL IN THE FUNCTIONALIST ARGUMENT OF FRITZ}

\section{KARL MANN}

\section{Abstract}

This article aims to examining and discussing the sociopolitical functions of tax as a means of social control in the perception of Fritz Karl Mann, one of the founders of fiscal sociology. From a hypothetical-deductive approach, this analysis develops around Mann's arguments to justify the correlation between the emergence of the tax state and its inclusion in the fields of functionalist sociology. In a second step, the work describes the notion of social control vis-à-vis the functionalist consciousness of the social fact, which is the link between the divisions that integrate this article. In the last part, this analysis exposes Mann's ideas and his effort to get social control vol.09, no. 04, Rio de Janeiro, 2016. pp. 1841-1864 
mechanisms, the main objective of this article. Finally, it is possible to note that Mann has developed with his research, a new horizon for tax further that its role as a mere provider of public treasury. Indeed, the tax burden of social life run through the several spheres of social sciences and interdisciplinary analysis is important, that way, as a condition for its validity in democratic societies.

Keywords: Tax. Socio-political function, Functionalist theory, Social control.

\section{REFERENCIAS}

AUDIER, Serge. Le socialisme liberal. Paris: La Découverte, 2006.

ARON, Raymond. As etapas do pensamento sociológico. 2. ed. Tradução de Sérgio Bath. São Paulo: Martins Fontes/Universidade de Brasília, 1987.

La lutte de classes - nouvelles leçons sur les sociétés industrielles. Paris: Gallimard, 1964.

Dix-huit leçons sur la société industrielle. Paris: Gallimard, 1962.

BELTRAME, Pierre. Famille et impôt: la prise en compte des charges de famille en droit fiscal français. In SACCHETO, Claudio (Org.). La tassazione della famiglia: aspetti nazionali e comparati. Turim: Rubbetino, 2010, pp. 19-32.

BENOÎT, Jean-Louis. Alexis de Tocqueville - textes essentiels. Paris: Pocket, 2000.

BOTTOMORE, T.B. Introdução à sociologia 9. ed. Tradução Waltensir Dutra, Patrick Burglin. Rio de Janeiro: Guanabara, 1987.

Elites and Society. Middlesex: Penguin Book, 1964.

BOUVIER, Michel. Monsieur le Président, discutons de la justice fiscal, il y a urgence. Les Echos, Paris, mai. 2012. Disponível em <http://lecercle.lesechos.fr/economie-societe/politique-ecoconjoncture/fiscalite/221 146709/monsieur-president-discutons-justice->. Acesso em: 11 mai.2012.

Introduction au droi $t$ fiscal et à la théorie de limpôt. Paris: LGDJ, 1996.

BOZIO, Antoine, Julien GRENET. Economie des politiques publiques. Paris: La Découverte, 2010.

CAMPBEL, John L. The State and Fiscal Sociology. In: Annual Review of Sociology, Cambridge, 19, 1993, pp. $163-185$

CASTRO, Celso A. Pinheiro de. Sociologia do Direito. 6. ed. Sao Paulo: Atlas, 1999.

DONZELOT, Jacques. L'invention du social. Paris: Editions du Seuil, 1994.

DOSTALER, Gilles. Le libéralisme de Hayek Paris: La Découverte, 2001.

DURKHEIM, Émile. As regras do método sociológico. 3. ed. São Paulo: Martins, 2014.

FALCÃO, Maurin A. Os efeitos da mudança social sobre o binômio tributação e democracia na sociedade pósRevolução Industrial. In: Direito, Estado e Sociedade, Rio de Janeiro, 43, 2013, p. 93-117. 
GENIEYS, William. Sociologie politique des élites. Paris: Armand Colin, 2011.

HAYEK, F. H. O caminho da servidão. 6. ed. Tradução Anna Maria Capovilla, José Ítalo Stelle, Liane de Morais Ribeiro. São Paulo: Insittuto Ludwig von Mises, 2010.

HEER, Clarence. Taxation as an Instrument of Social Control. In: American Journal of Sociology, 42, 4, 1937, p. 484-492.

HOBSON, John M. The wealth of states - A comparative sociolog of international economic and political change. Cambridge: Cambridge University Press, 1997.

LEROY, Marc. L'impôt, l'État et la société - la sociologie fiscale de la démocratie interventionniste. Paris: Economica, 2010a.

Sociologie de la fiscalité de la famille. In: SACCHETO, Claudio (Org). La tassazione della famiglia: aspetti nazionali e comparati. Turim: Rubbetino, 2010b, pp. 143-168.

MANN, F. K.The sociology of taxation. In: Review of Politics, 05, 1943, p. 225-235.

MANNHEIM, K. Sociologia Sistemática: uma introdução ao estudo de sociologia. 2. ed. São Paulo: Pioneira, 1971.

MARCHAND, Christophe. Economie des interventions de l'État. Paris: Presses Universitaires de France, 1999.

MEYNAUD, Jean. Les groupes de pression. Paris: Presses Universitaires de France, 1960.

MISES, Ludwig von. A mentalidade anticapitalista. Tradução Carlos dos Santos Abreu. Campinas: Vide Editorial, 2013.

MUSGRAVE, R.A. The Theory of Public Finance. New York: Mc Graw-Hill, 1959.

NIKONOFF, Jacques, DREZET, Vincent. Vivent les impôts. Paris: Mille et Une Nuits, 2005.

PARSONS, Talcott. Les systèmes des sociétés modernes. Tradução Guy MELLERAY. Paris: Dunod, 1973.

PERISSINOTTO, Renato. As elites políticas - questões de teoria e método. Curitiba: IBPEX, 2009.

PIKETTY, Thomas. L'économie des inégalités. 6. ed. Paris: La découverte, 2008.

ROSANVALLON, Pierre. La société des égaux Paris: Editions du Seuil, 2011.

A crise do Estado-providência. Tradução Joel Pimentel de Ilhôa. Brasília: Universidade de Brasília, Universidade Federal de Goiás, 1997.

La nouvelle question sociale - repenser l'Etat-providence. Paris: Editions du Seuil, 1985.

ROSA, Audrey. Solidarité et impôt: recherché sur les fondements de l'impôt moderne. Paris: Dalloz, 2015.

STEINMO, Sven. Taxation \& Democracy: Swedish, British, and American approaches to financing the modern state. New Haven, London: Yale University Press, 1983. 
WALRAS, Léon. Éléments d'économie politique. Paris: Librairie Général de Droit et de Jurisprudence, 1952.

Trabalho enviado em 11 de fevereiro de 2016.

Aceito em 02 de junho de 2016. 